Arteterapia. Papeles de arteterapia y educación para inclusión social ISSN-e 1988-8309

http://dx.doi.org/10.5209/ARTE.57570

\title{
El garabato de Winnicott y su uso inspirador en arteterapia
}

\author{
Paz Martínez Loné
}

Recibido: 15 de marzo de 2017 / Aceptado: 29 de julio de 2017

Resumen. A partir del caso Liro (Winnicott 1971) y del juego del garabato en una única consulta terapéutica, se despliegan algunos fundamentos teóricos y prácticos del arteterapia en los que el encuentro con el autor es permanente: el jugar, la contratransferencia, el diálogo con las obras y el ofrecer al paciente oportunidades para expresarse y explorar diferentes modalidades expresivas que favorezcan la comprensión de sí mismo y la integración psíquica.

Palabras clave: creatividad, jugar, juego del garabato, transfer intermodal.

\section{[en] Winnicott squiggle game and its inspiring use in art theraphy}

\begin{abstract}
Taking the Liro case (Winnicott 1971) and the squiggle game as a starting point, in a single therapeutic consultation, some theoretical bases and techniques of art therapy are presented, providing a permanent encounter with the author: playing, countertransference, dialogue with the work produced and opportunities for the patient to express themself and explore different modes of expression to enable self understanding and psychic integration.

Keywords: creativity; playing; squiggle game; intermodal transfer.
\end{abstract}

Sumario.1.Introducción. 2. Vivir creativamente. 3. Jugar con Winnicott. 4. El caso Liro. 5. Más allá de las palabras. 6. El proceso creativo entre polaridades. 7. El picnic le pertenece al paciente. 8. Referencias bibliográficas.

Cómo citar: Martínez Loné, P. (2017). El garabato de Winnicott y su uso inspirador en arteterapia, en Arteterapia. Papeles de arteterapia y educación para inclusión social 12, 191-203.

\section{Introducción}

El presente artículo es una integración del trabajo de fin de máster que realicé en 2013 en el que profundizaba en los fundamentos del arteterapia y su aplicación en contextos de salud mental y del libro del que soy coautora junto con Alba Gasparino, doctora en psicología, publicado en 2016 sobre el garabato de Donald Winnicott.

1 Directora del Centro de Pisicoterapia Latrama. Psicoterapeuta, arteterapeuta y coautora del libro El garabato de Winnicott en la pareja y el grupo.

Email: pazmartinezlone@gmail.com 
En concreto, amplío aquí el capítulo en el que el squiggle inspira el trabajo de los arteterapeutas y favorece el trabajo intermodal en el que el paciente realiza transfer artístico de una modalidad de expresión a otra (escritura, pintura, dramatizaciones, danza, etc.) siendo el jugar Winnicottiano el hilo conductor que permite que en cada obra creada se amplíe la mirada y se abran interrogantes.

Desde el primer caso que el autor expone en Clínica Psicoanalítica Infantil (1971), el caso Liro, iré desplegando algunos fundamentos básicos del arteterapia. Mi propósito es danzar con las palabras en un ir y venir de las teorías a las historias, de los conceptos a las anécdotas y de las ideas a las imágenes.

\section{Vivir creativamente}

El nombre de Donald Woods Winnicott (Plymounth, 1896- Londres, 1971) está ligado a la idea de vivir creativamente. No necesariamente a través de la realización de obras de arte talentosas, que supondrían un tipo de creatividad más sofisticada, sino como una actitud natural y espontánea que colorea todo aquello que hacemos e implica sentirnos auténticos, vivos. El autor diferencia entre el vivir creador y la creación artística. El impulso creador no es exclusivo de los artistas, sino que cualquier persona lo puede desarrollar e incorporar a su vida simplemente disfrutando de un paisaje hermoso, escuchando el sonido de de nuestra respiración, cocinando o regando las plantas. La capacidad de vivir creativamente es una necesidad y una experiencia universal que todos podemos desarrollar. Sucederá en las primitivas etapas de la vida del bebé, si existe un adecuado ambiente facilitador (Gasparino y M. Loné, 2016).

Winnicott plantea dos nacimientos: el biológico y el psíquico, mediatizado éste último por la relación que el bebé establece con su madre o cuidador primario. Su paradoja fundamental es que el bebé no existe, pues lo que existe es la pareja de crianza. La madre suficientemente buena, a través de las tres funciones estructurantes del psiquisimo del bebé (holding, handling y object presenting) y de la constancia en su cuidado, asegurará la continuidad existencial del bebé y garantizará que se despliegue de forma espontánea su desarrollo emocional y creatividad. Lo fundamental para Winnicott es que cada persona llegue a ser ella misma desplegando su self verdadero.

Vivir creativamente sería una condición para sentirnos vivos y estaría posicionada en el continuo salud-enfermedad en el polo de lo sano. En el extremo opuesto, en la polaridad de lo que enferma, estaría el acatamiento: la sobre adaptación a los mandatos de la realidad y el estar alienados en la creatividad de algún otro: persona, grupo, modelo teórico o institución. El acatamiento conduciría a sentimientos de futilidad y a la vivencia de que la vida no es digna de ser vivida.

La creatividad, para nuestro autor es por tanto un indicador de salud que el terapeuta ha de rastrear desde el primer encuentro con el paciente. Winnicott estaba convencido de que la creatividad nunca se destruye por completo y aún en lo peor de las situaciones, como aquellas de sometimiento extremo, regímenes dictatoriales, campos de concentración, etcétera, el ser humano es capaz de encontrar recursos para un vivir creativo, una vida secreta en la que encontrar satisfacción porque es inédita y original para la persona. Resueno con él pensando en obras que se crearon en ambientes muy poco facilitadores como las esculturas de Judith Scott, quien en- 
contró en el tejer un modo de expresión a través del cual salir de su jaula de silencio o el testimonio artístico de muchos artistas judíos que sobrevivieron a la Shoah y se jugaron la vida en los campos de exterminio intentando dejar una huella expresiva de la naturaleza humana. Muchos de estos artistas son anónimos y otros como Nelly Toll o Leo Hass han adquirido relevancia en el mundo del arte, formando sus obras parte del "Arte del Holocausto".

\section{Jugar con winnicott}

Jugar está profundamente ligado a la idea de vivir, pues nuestra verdadera esencia está en el juego: somos como jugamos. Winnicott fue un pediatra comprometido y un analista que jamás perdió la mirada de niño. Le gustaba montar en moto, el teatro y nadar. Cantaba, tocaba el piano entre paciente y paciente en su consultorio de Chester Square y era un gran seguidor de los Beatles. Escribía poemas y dibujaba de forma autodidacta. En sus relatos clínicos encontramos un hombre con un acentuado humor (inglés) y es habitual encontrar fotografías de la época en las que aparece con una actitud lúdico- artística. Cuando pienso en Winnicott, me asaltan algunas imágenes que he leído en algunas de sus biografías (Kahr, 1996) el pediatra que calentaba el fonendo con las manos antes de explorar a los niños en el frío Londres, o el Winnicott que dibujaba postales de navidad junto con su segunda esposa, Clare, para enviárselas a sus amigos.

Winnicott hace de su manera de entender la vida su área de investigación y su aporte personal al psicoanálisis. Jugar constituye la posibilidad de crear, soñar y vivir. Es en el espacio transicional, en la zona intermedia de experiencia que se sitúa entre la realidad psíquica y la realidad externa donde se desarrolla el juego y la actividad creadora y donde se abren espacio los fenómenos transicionales. Esta zona intermedia es un lugar de descanso, la zona sagrada a la que acudimos cuando nos divertimos y disfrutamos y la zona desde donde trabaja el arteterapia.

A Winnicott no le interesa tanto el juego (play) del niño: su simbolismo, la trama narrativa, sino el niño que juega (playing) el proceso y la capacidad de jugar. El garabato, juego libre, no convencional y no reglado es un juego espontáneo en el que alternativamente cada miembro de la pareja bosqueja un garabato que el otro completa y transforma en algo reconocible. Algo así como jugar a encontrar formas en las nubes, salvo que en el garabato, la resultante es una creación transicional de autoría compartida (Lacruz, 2011)

El objetivo terapéutico es desplegar la capacidad de jugar del paciente, su gesto espontáneo y desde un encuadre humano, crear con él una comunicación profunda en la que se sienta comprendido y alentado de que el terapeuta le puede ayudar, así como favorecer su integración psíquica (Lacruz, 2010)

La primera publicación sobre el squiggle es en 1953, en la conferencia "La Tolerancia de síntomas en Pediatría”, en la Sección de Pediatría de la Real Sociedad de Medicina de Gran Bretaña. Hasta 1968 y por temor a estereotipar su creación y convertirlo en algo ritualizado, en una técnica proyectiva que despoje al juego de su calidad de espontáneo y original, no publicará ningún otro comentario hasta que escribe El juego del garabato, que amalgama un artículo inédito de 1964 y otro publicado en 1968. Sin embargo, la generosidad y esperanza de su buen manejo, 
lo conducen a facilitarnos las pautas básicas del mismo en Clínica Psicoanalítica infantil (1971) donde describe y suministra detalles sobre la realización del juego (Gasparino y M. Loné, 2016).

Winnicott jugaba a garabatos en el Paddington Green Children's Hospital en lo que con su particular humor llamaba Psychiatric Snack bar (cafetería psiquiátrica) enmarcando el juego en una modalidad de entrevista o primeras entrevistas que denominaba consultas terapéuticas. Dichas consultas tienen un doble objetivo: diagnóstico y terapéutico en un tiempo limitado de uno a tres encuentros. El objetivo diagnóstico implica determinar el grado de rigidez y flexibilidad de las defensas, mientras que el terapéutico aboga por provocar un cambio en el paciente en el aquí $\mathrm{y}$ ahora de la sesión. Para ello el terapeuta ofrece un espacio transicional o una zona de juego estable y dinámico en el que se promueva el gesto espontáneo del paciente, que si se siente comprendido, traerá su preocupación en su jugar (Lacruz, 2011).

\section{El caso Liro}

El primer relato de Clínica Psicoanalítica Infantil (1971) es el caso Liro, un niño Finlandés de 9 años y 9 meses a quien Winnicott conoció mientras visitaba el Hospital Infantil de Kuopio en Filandia. El equipo médico propuso a Winnicott que realizara una exposición tomando por caso clínico a algún paciente del hospital. Pensaron en Liro porque ingresado en el Servicio de Ortopedia del hospital, había sido intervenido quirúrgicamente en múltiples ocasiones de manos y pies presentando una actitud muy colaboradora que extrañaba a sus cirujanos.

Liro tenía sindactilia, enfermedad congénita en la que los dedos están unidos entre sí. No padecía ninguna patología psiquíatrica, aunque sí algunas somatizaciones recientes: cefaleas, dolor abdominal y falta de apetito.

Como Liro únicamente habla finés y Winnicott inglés, se sirven inicialmente de una psicóloga (la señorita Kelka Asikainen) que hace de traductora, si bien una vez empieza el juego la traducción se hace innecesaria. El encuadre se realiza con dos lápices y varios folios sobre la mesa que se rompen en pedazos, para restar trascendencia y alejar el garabato de los tests proyectivos en los que el evaluador se coloca en una posición de mucha mayor asimetría. Winnicott explicaba el garabato con sencillez:

Cierro los ojos y hago así en el papel, y tú lo conviertes en algo; luego te toca a ti, procedes de la misma manera y yo lo convierto en algo (Winnicott, 1971).

El primer garabato que hace Winnicott es transformado por Liro en una pata de pato, por lo que el terapeuta deduce que Liro trae a escena una preocupación en relación a su dificultad con las manos. Los siguientes garabatos ahondan en los patos y cómo estos nadan por los lagos. El analista trata de escuchar y mostrar simpatía y confianza con el niño. Más adelante los garabatos cambian y el niño empieza a hablar de música. Comenta que puede tocar un poco el piano y Winnicott, aprovecha que ha creado un buen clima con él para utilizar su sentido del humor refiriéndose por primera vez al material. 
Viendo que Liro era un niño saludable y que tenía sentido del humor, le dije que sería difícil para un pato tocar la flauta, y eso lo divirtió. (...) No le expliqué que estaba representando su propia incapacidad por medio de patos. Eso hubiera sido una torpeza (Winnicott, 1971).

Tras un garabato del terapeuta con forma de mano que Liro rápidamente transforma en una flor (eludiendo hablar de su conflicto) aparece otro muy parecido a su mano deformada. El niño comenta que le ha salido sin pensar y es entonces cuando Winnicott, sin interpretar, le pregunta por sus sueños. El pequeño responde que en su mayoría son agradables y el analista no insiste.

En el siguiente garabato Liro hace un dibujo que se parece bastante a su mano izquierda y Winnicott se lo señala. Es entonces cuando Liro habla de todas las intervenciones que ha sufrido y las que tiene aún que enfrentar en manos y pies. Winnicott entiende que querría ser todas esas cosas que no puede hacer (tocar la flauta, hacer trabajos manuales). En un dibujo posterior que el niño hace de una anguila que devuelve al mar por ser demasiado pequeña, Winnicott infiere que está hablando de su estado emocional primitivo y se anima a interpretarle que pese a que se quiere tal y como es con sus manos y pies palmeados como un pato, le hubiese gustado ser aceptado y amado tal y como vino al mundo antes de que el proceso de transformación quirúrgica empezase. En un garabato posterior Liro vuelve a dibujar su mano izquierda muy sorprendido. Winnicott le desafía con un garabato muy complicado a reanudar el juego que concluye cuando el niño vuelve a dibujar un pato.

Este caso, tiene una segunda parte en la que el analista se entrevista durante una hora con la madre del niño. En lágrimas, la madre expresa sentirse muy culpable de que Liro haya heredado su misma enfermedad y reconoce haberle odiado y repudiado al nacer hasta que se obsesionó por corregir esos defectos con cirugía. Su atención se centró tanto en Liro que acabó convirtiéndose en su hijo más querido. El pequeño expresaba este sentimiento de ser amado a través de su amor por los patos, por eso accedía a operarse sin resistencias. Sin embargo, existía un deseo más profundo de ser querido y aceptado tal cual se vino al mundo.

\section{Más allá de las palabras}

Este caso nos habla de una forma de comunicación en la que se da un entendimiento profundo con muy pocas palabras. Obviamente este aporte es muy inspirador para todos los arteterapeutas que trabajamos con personas cuyo lenguaje no se ha desarrollado o presenta alteraciones (niños, autismo, diversidad funcional, demencias severas etc.) donde las obras y la comunicación analógica es el sistema de comunicación predominante, si bien una parte del lenguaje verbal sigue presente.

Al prestar atención al lenguaje corporal de sus pacientes, el arteterapeuta está convocado a tener conciencia sobre su propia corporalidad: movimientos, gestos, tono de la voz, miradas, sonrisas, proximidad, y en general a todas las manifestaciones contrataransferenciales.

El arteterapia hace hincapié en el proceso de trabajar con imágenes más que en el producto final (Allen, 2010). En este sentido, es importante aprender a dialogar con nuestras obras: ¿de qué nos hablan?, ¿qué sensaciones nos generan?, ¿a qué otras obras nos remiten, propias o de otros artistas o referentes?, ¿Qué nos gusta de 
la obra, qué nos molesta especialmente? ¿Qué es aquello que capta nuestra atención, que nos captura? El proceso creativo es en sí un diálogo entre el espacio en blanco y el autor donde las conversaciones surgen, no se planean.

Cassirer habla de la vida propia de las obras que alcanzan su propia autoridad (Pozo, 2008). En lugar de intentar clasificar las imágenes desde nuestro marco de referencia, el arteterapia trata de dialogar con ellas, contar historias sobre cómo se han creado, averiguar de dónde vienen, interrogarlas, escuchar lo que dicen, dramatizarlas a través de los movimientos que imprimen a nuestros cuerpos y soñar con ellas. (McNiff, 2012). El diálogo con las imágenes se basa en la aceptación de la vida autónoma de las mismas y el rol del arteterapeuta y del creador-autor que ha hecho posible que aparezcan ha de ser el de una persona que escucha lo que las imágenes tienen que decir a través de él y no el de una persona que explica e interpreta lo que significan. El diálogo con la obra, no impone, domestica ni manipula. Se trata de atender a la figura que emerge y que casi siempre genera una sorpresa.

Liro se sorprende de que el garabato de su mano izquierda, deformada por las operaciones se repita con insistencia quizás a pesar suyo. La mano deformada nos habla de un punto de emergencia y de un atasco en el desarrollo emocional, puesto que allí donde hay un estancamiento de la creatividad, encuentra Winnicott neurosis.

El arte actúa interrogando las zonas del cuerpo y el psiquismo que tenemos congeladas y el arteterapeuta ha de saber captar este momento a la vez que respetar el tempo del paciente. Winnicott es un buen ejemplo de cómo hacerlo: No interpreta a Liro su repetición, sino que es el propio niño quien sorprendido dice: "Me ha salido esto otra vez". El analista le anima a que siga asociando y añadiendo imágenes a su obra interesándose por sus sueños.

Winnicott (1979) decía que la psicoterapia se da en la superposición de dos zonas de juego la del paciente y la del terapeuta y que si éste último no sabe jugar, o no está dispuesto a hacerlo, entrando en tarea con y desde su propio inconsciente, no podrá ayudar a que su paciente lo haga. Para ello, el terapeuta, ha de ser muy consciente de su contratransferencia. No debe invadir al paciente, pero no puede estar congelado. Como un instrumento musical, ha de estar afinado y poder resonar las vibraciones que llegan de su paciente. El arteterapeuta ha de estar conectado consigo en una actitud de cuerpo vibrátil que se aleje de los discursos del poder y pueda escuchar y acoger lo incomprensible, lo informe, lo nunca antes pensado, lo desconocido, lo ajeno, lo que no encaja con el propio modelo teórico, etc. (Sorin, 2011).

Vibrar y estar despierto implica estar presentes en el aquí y ahora de la sesión e incorporar al sentido de la lógica (lo racional, lo intelectual), la lógica de los sentidos (Deleuze 1971), la experiencia vivencial que recogería lo sensorial, lo perceptual, lo intuitivo.

Imaginar cómo sería una determinada sesión con un paciente en forma de danza, o bailar esa sesión, dibujar con diferentes colores e intensidades cómo serían las aportaciones del paciente y las nuestras es una manera de retraducir y explorar en diferentes registros expresivos cómo es ese vínculo. En el tránsito de una disciplina a otra (danza, poesía, escultura) encontramos una nueva creación que nos ayuda a interrogarnos, a profundizar enfocando en un aspecto específico atendiendo lo molecular, o abriendo foco atendiendo a lo molar. Cada modalidad expresiva funciona como un idioma diferente que nos permite expresarnos de manera singular en cada uno. El ejercicio final sería por tanto la integración psíquica. 
A medida que vamos teniendo práctica en el pensamiento en imágenes, y en el uso de metáforas, este tipo de pensamiento, que Fiorini (2004) llama terciario, se incorpora como una dimensión más que atraviesa al arteterapeuta. Además de la escucha analítica incorporará la dimensión estética y de forma casi involuntaria, empezará a pensar en sus pacientes y en los vínculos que crea con ellos terapéutica y artísticamente. Pondré un ejemplo: Durante años trabajé en un dispositivo de rehabilitación para atender a personas con enfermedad mental, psicosis fundamentalmente. La dimensión estética, me permitió pensar en la locura metafóricamente. Es así como empecé a pensar en los pacientes como islas y en mi trabajo como en la creación de archipiélagos dentro de la sala de grupos.

Algunos pacientes me parecían islas mareales: islas que se unen a tierra firme cuando baja la marea a través de un camino y vuelven a parecer islas cuando la marea sube. Conexión, desconexión, cerca, lejos., neurosis, psicosis... Pensar en la locura artísticamente nos permite, además de atender a los criterios diagnósticos necesarios en nuestro ejercicio profesional, a comunicar con las personas desde lo que nos une a ellas y no exclusivamente desde lo que nos separa. Mirar al loco como una isla (en ocasiones, mareal) me permite comprender que con infinita menor intensidad existe un registro de la locura en mi con el que puedo sintonizar para crear una comunicación profunda.

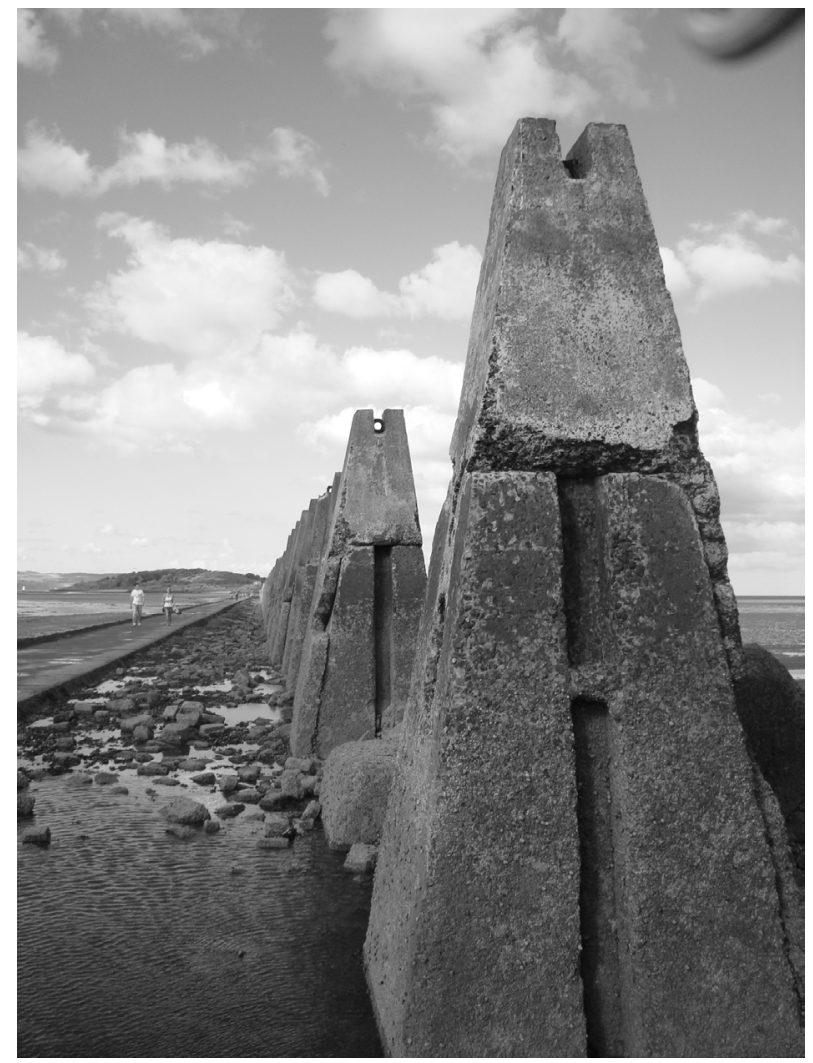

Figura 1. Pie de foto: Isla mareal de Cramond, Edimburgo. 


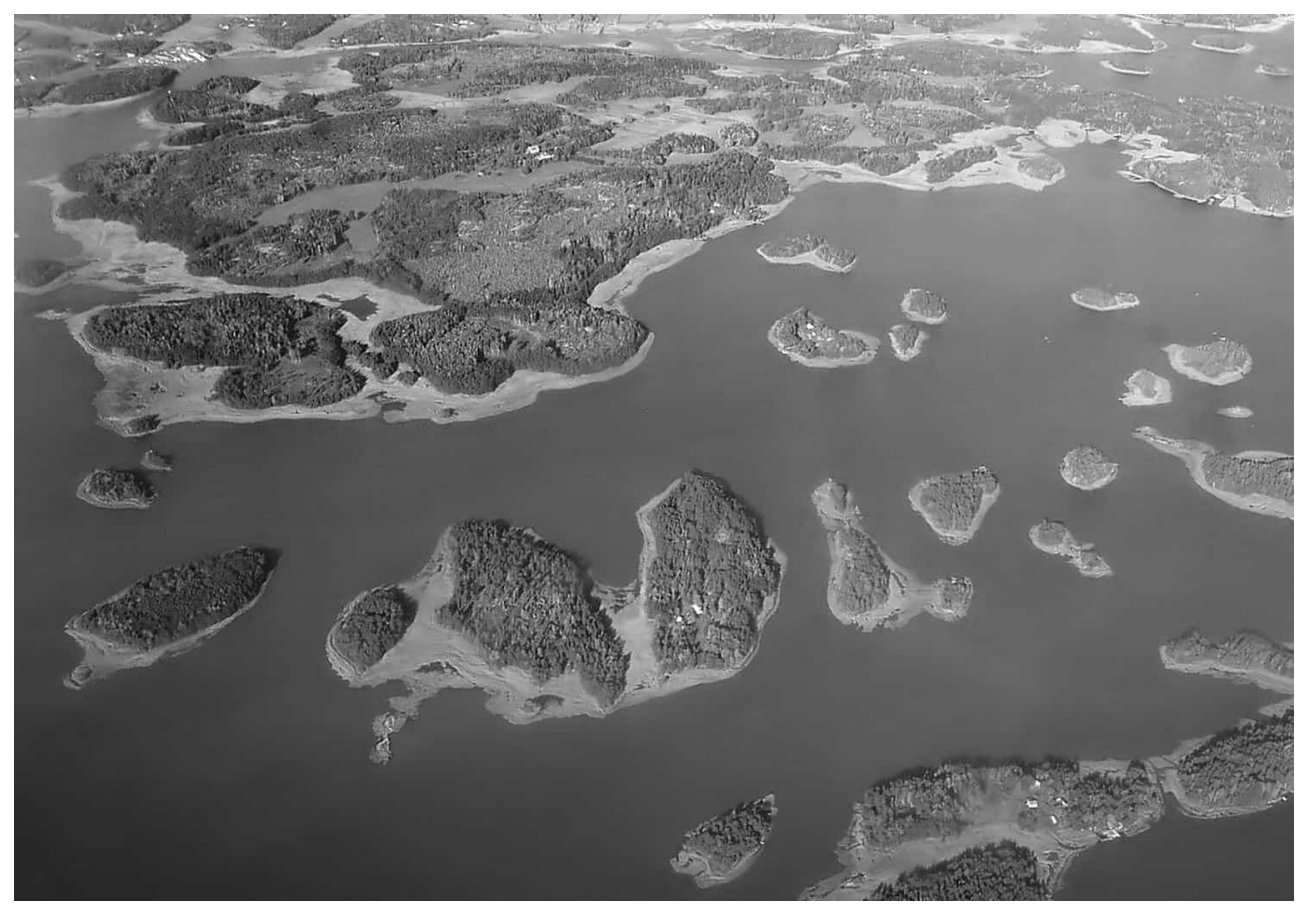

Figura 2. Pie de foto: Creación de archipiélagos, pacientes que se conectan a través de la terapia de grupo.

Dice Fiorini (2004) que el arte siempre suma, pues nos descubre que otras formas son posibles: otro trazo, otro color, otro movimiento, otra perspectiva, otra mirada... este factor contrasta bruscamente con la enfermedad, que es el mundo de la estereotipia en el que la posibilidad está coartada.

En la misma línea me gustaría comentar otro ejemplo en el que la intuición facilitada a través de la mirada estética, entra en el cuerpo sin pedir permiso, con un insight certero. Son las ocasiones en las que la metáfora artística antecede a la diagnóstica. En el mismo dispositivo de rehabilitación, un paciente de treinta años ex militar, relata su entrada en la psicosis y el vía crucis psiquiátrico en el que ha estado los últimos años: numerosos ingresos involuntarios, clínicas privadas, cambios bruscos de medicación, abuso de sustancias, intentos autolíticos y mucha culpa por generar sufrimiento a su madre diagnosticada de cáncer y no satisfacer la expectativa de un padre también militar y con una carrera boyante. Decía beber dos litros de Coca-Cola al día y otros dos de Red-Bull para sentirse despierto y en un estado de embriaguez parecido al que le proporcionaban los tóxicos. A menudo, cuando no soportaba aquello en lo que se había convertido, se cortaba con un cúter para aliviar el dolor emocional.

De pronto, una paloma que sobrevolaba cerca de la ventana, se estampó contra el cristal bruscamente y cayó desplomada al suelo dejando un reguero de sangre en el cristal. La escena fue devastadora y de inmediato intuí que cuando el paciente llegara a casa se intentaría quitar la vida, como si aquella paloma fuera un emergente en forma de metáfora de lo que podía acontecer. Un día más tarde la llamada del hospital confirmaba la intuición. 
Dice Vasili Kandisky (1996) que en el arte la teoría nunca va por delante arrastrando tras de sí la praxis, sino que sucede lo contrario, pues lo artísticamente verdadero sólo se alcanza a través de la intuición. Desarrollar esta intuición y alojarla en el cuerpo téorico del arteterapeuta; en su bagaje clínico, nos ayuda a integrar estas dos lógicas complementarias.

\section{El proceso creativo entre polaridades}

Otro aspecto en el que la obra de Winnicott inspira el trabajo arteterapéutico es el proceso creativo que se despliega en el espacio intermedio entre polaridades. En el caso Liro, observamos cómo el psicoanalista se muestra atento al momento en que niño apunta a la sindactilia de su mano. Sin embargo, al tiempo que la registra en el orden de lo detenido y psicopatológico, explora la capacidad de Liro para soñar, comunicarse, vincular y encajar el sentido del humor. En la misma sesión se interesa por averiguar los males y síntomas de la persona así como en consignar sus recursos personales.

Como plantea Fiorini, (2004) cada vez que un paciente realiza una consulta que es motivo de un trabajo terapéutico es porque existe, además del sufrimiento que trae, algún proyecto que en líneas generales trataría de ser una alternativa a ese sufrimiento. La tarea del arte-terapeuta, sería la de pivotar entre el inconsciente del sufrimiento y el inconsciente del proyecto.

El trabajo con las polaridades nos sirve para encontrar recursos personales que nos ayuden a transitar de una a otra. Así, si en una sesión voy a trabajar el reencuentro con la tristeza de un paciente, intentaré generar imágenes de alegría previamente, que creen un "refugio" del que poder entrar y salir. También nos sirve para descubrir que aquello que los pacientes muchas veces llaman "defectos" son también parte de su fuerza vital, de sus virtudes.

En la construcción de nuestra personalidad, hemos ido definiendo nuestro autoconcepto de una manera fija, estática, sin movimiento. Esa identificación con algunos aspectos de nosotros mismos nos hace rígidos porque en la afirmación de lo que somos negamos aspectos propios que no nos gustan tanto. En la experiencia arteterapeútica, se pone de manifiesto esa lucha entre lo que creo que soy y lo que se manifiesta de mí, entre lo que acepto y rechazo, muestro y escondo. Es en el proceso creativo a través de las obras donde es posible establecer un diálogo entre estas dos polaridades sin juzgarlas, permitiendo que sean y se expresen al mismo tiempo, no una u otra, sino una y otra, brindando un espacio de juego, en el que es posible la integración de ambas.

En el continuo de polaridades que habita a las personas, podemos encontrar múltiples personajes diferentes. Fernando Pessoa introdujo el concepto de heterónimo en literatura, él los denominaba otros de él mismo. Llegó a tener setenta personajes con personalidades distintas, escribiendo una obra poética distinta para la mayoría de ellos. Uno de los heterónimos que podría utilizar Liro en una consulta de arteterapia sería ese pato que aparece en sus dibujos. Le invitaríamos entonces a que jugara con ese pato: lo dibujase, le pusiera un nombre, escribiera un cuento sobre su procedencia y caminara como él. Jugaríamos a ponerle voz y a escribir la lista de los deseos de ese pato, así como todas las cosas que le dan miedo... El juego del niño es ilimitado 
y el arteterapeuta ha de estar atento y estimular el "transfer" creativo del paciente para que en el ir y venir de una disciplina artística a otra se abran nuevos lenguajes e interrogantes.

El trabajo con heterónimos, utilizando el humor y la desdramatización, opera de manera especialmente útil para jugar a explorar e integrar esas otras partes nuestras. Al tratar a estos personajes como seres independientes a uno mismo y dialogar con ellos, descubrimos diferentes facetas de nuestro yo, con las que aprendemos a convivir. Aprender a aceptar estas partes y reírse de ellas, da lugar a que, en palabras de Pichon-Rivière, lo siniestro se transforme en algo maravilloso (Fabris, 2007).

En ocasiones, en pacientes con un uso acentuado de la defensa intelectual que tienden a psicologizar en exceso, constituyen una manera más amable de nombrar aspectos de uno mismo: una paciente de 34 años, trabaja en consulta sus tendencias masoquistas (boicoteos profesionales, sumisión en varias relaciones de pareja, huidas hacia delante a través de largos viajes que la desarraigan, consumos peligrosos, promiscuidad etc.).A partir del garabato de una llave que no logra integrar en la narración espontánea que hace de todos los demás garabatos que aparecen en el juego, aparece un sueño en el que se interroga por los límites, el morbo que genera lo prohibido y las consecuencias de traspasar estos límites. Unos meses después asocia con un cuento: Barba Azul. Inicialmente lo relaciona con todos los personajes que en su vida han intentado asesinar su esencia. Con posterioridad, en un momento doloroso, se da cuenta que ese Barba azul es el masoquismo del que hemos estado hablando varios meses y que encarna un aspecto propio de su personalidad. La posibilidad de negociar con este personaje, de retarle y enfrentarle, generó múltiples posibilidades: pudo reírse de ella misma y decir que "hoy tenía el barba azul acentuado" en vez de insultarse una vez más llamándose masoca.

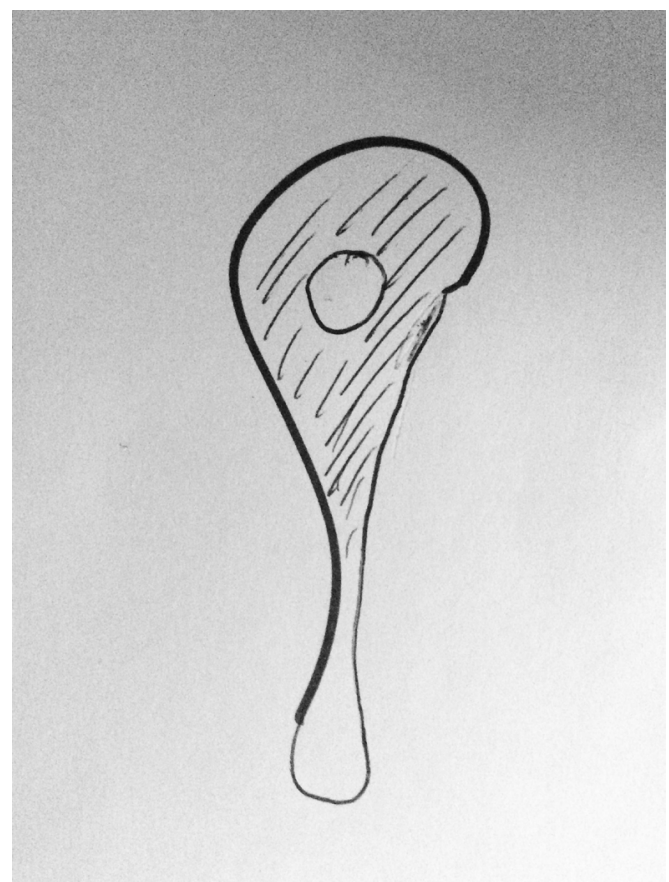

Figura 3: Garabato que la paciente transforma en una llave. 


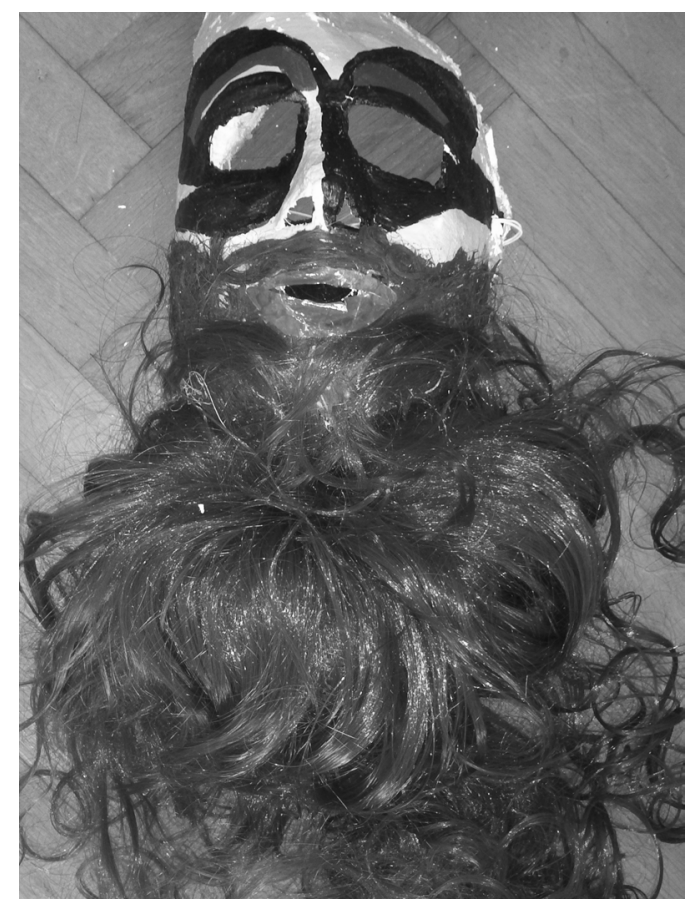

Figura 4: Máscara de Barba Azul que realiza tras hacer insight con el cuento.

Winnicott no es un terapeuta de rol estático (Fiorini, 2004). En su técnica pasa de mostrarse muy presente: coge la mano a sus pacientes, lagrimea en una sesión ayudando a llorar a una paciente (Little, 1995), envía una foto suya a una antigua paciente que se la solicita por carta, negocia condiciones de ingreso psiquiátrico etc. y muy ausente en otras: permite dormir a un paciente en el diván para ofrecerle una segunda oportunidad en el desarrollo de adquirir la capacidad de sentirse solo en presencia del otro. Se muestra hablador y silencioso (apuntando sus interpretaciones al margen de las hojas), pasa de la realidad al sueño, de las preocupaciones a las ilusiones, etc.

Resulta fundamental que como arterapeutas incorporemos la dialéctica antitética y trabajemos con la salud y la enfermedad de nuestros pacientes, con su violencia y su ternura, su tristeza y su alegría, etc. desde los primeros encuentros. Si sólo preguntamos por sus problemas, transmitiremos sin llegar a expresarlo, un interés únicamente en ellos. Si por el contrario, el paciente advierte interés por sus recursos personales, se le estará infundiendo aliento de forma indirecta para percibirse así mismo con mayor vigor. La mejor alternativa sigue siendo mostrar el mismo interés por ambas facetas (Reddemann, 2003). De esta manera ayudaremos al paciente a sentir que es capaz de generar por sí mismo un nuevo escenario, una nueva realidad en la que él es el capitán de su alma, el único artista de su proceso. 


\section{El picnic le pertenece al paciente}

Podríamos pensar que un abordaje posible del caso Liro hubiera sido intentar comprender el sentido de los síntomas. Sin embargo, el analista no cesa de decirnos que el picnic le pertenece al paciente (Winnicott, 1991) y que es él quien dirige la entrevista.

Liro tiene una mano "de pato" y dibuja un pato. Podríamos pensar que estábamos ante una buena oportunidad para abordar la sindactilia. Sin embargo Winnicott no interviene y deja que sea Liro quien traiga su enfermedad cuando desee. Nuestro autor insiste en que es posible realizar una terapia profunda a través del juego sin necesidad de emitir interpretaciones. Lo cual no significa que no puedan hacerse, sino que lo verdaderamente importante y causa de efecto terapéutico en el paciente es el momento oportuno en que el niño o adulto pueda sorprenderse y hacerla propia incluso por un señalamiento o una aclaración en medio de su juego.

Si la interpretación no surge del juego conjunto, bien porque el analista no sabe jugar, o porque no puede o no quiere desprenderse de su lugar de supuesto saber, será vacua y se recibirá con confusión en el niño, adoctrinándole, sin reconocer su individualidad e historia personal así como los condicionantes de su entorno socio-cultural. En sus consultas terapéuticas (Winnicott, 1971) nos asombra la escasez de interpretaciones, como el manejo del silencio. Con él buscaría no interrumpir la secuencia de la elaboración que el paciente mismo puede estar construyendo. La interpretación está justificada si emerge del juego mutuo, en este caso se comparte un idioma común. El analista no inventa nada, sólo recicla materiales que ya estaban en la escena del juego (Gasparino, M. Loné 2016)

En arteterapia la interpretación se deriva del proceso de creación y su uso más singular y común es otra propuesta creativa, otro acto creador sobre lo creado que muchas veces surge del propio paciente en contacto con la obra que emerge (Coll, 2006). Otras veces, parten del arteteapeuta y buscan transmitirse de modo que los pacientes se sientan invitados a averiguar algo sobre sí mismos (Reddeman. 2003) y no sepultados por las palabras de un terapeuta que sabe demasiado y quizás no está dispuesto a ocultarlo.

A menudo descanso la mente escribiendo las interpretaciones que en la práctica no transmito. Mi recompensa por abstenerme de efectuarlas llega cuando las hace el propio paciente, quizás una o dos horas después. Mi descripción equivale a un ruego a todos los terapeutas, de que permitan que el paciente exhiba su capacidad de jugar, es decir, de mostrarse creador, en el trabajo analítico. Esa creatividad puede ser robada con suma facilidad por el terapeuta que sabe demasiado. Por supuesto, en realidad no importa cuánto sabe éste, siempre que pueda ocultar sus conocimientos o abstenerse de divulgarlos. (Winicott, 1979)

\section{Referencias Bibliográficas:}

Allen, P. (2010) Arteterapia guía de autodescubrimiento a través del arte y la creatividad. Madrid. Editorial Gaia.

Coll, F. (2006) Arteterapia, Dinámicas de creación y procesos arteterapeúticos. Murcia. Univerdidad de Murcia. 
Deleuze, G. (1969) La lógica del sentido. Barcelona. Editorial Paidós.

Fabris, F. (2007) Pichón-Rivière un viajero de mil mundos. Buenos Aires. Editorial Polemos. Fiorini, H. (2004) El psiquismo creador. Victoria-Gastéiz. Editorial Agruparte.

Gasparino, A. y M. Loné .P. (2016) El garabato de Winnicott en la pareja y el grupo. Madrid. Editorial Psimática.

Kahr, B. (1999) Donald Woods Winnicott Retrato y biografia. Madrid. Editorial Biblioteca Nueva.

Kandisky, V. (1996) De lo espiritual en el arte. Madrid. Editorial Paidós.

Lacruz, J. (2010) El juego del garabato (squiggle).Zaragoza. Recuperado de http://www.dibujoinfantil.com/articulo26.

Lacruz, J. (2011) Donald Winnicott vocabulario esencial. Zaragoza. Mira Editores.

Little. M. (1995) Relato de mi análisis con Winnicott. Buenos Aires. Editorial Lugar.

McNiff. S. (2012) Art as medicine, creating a therapy of the imagination, Boston \& London. Editorial Shambhala publications.

Pozo Gutiérrez, A. El arte como pensar metafórico en la filosofía simbólica de Cassirer. Revista Praxis Filosófica nº 26, enero- junio 2008. P 169.168

Reddemann, L. (2003) La imaginación como fuerza curativa. Barcelona. Editorial Herder.

Sorin, M. (2011) El arte y la persona. Arteterapia: esa hierbita verde. Barcelona. Editorial Ispa.

Winnicott, D. (1991) Exploraciones psicoananlíticas II, Buenos Aires. Editorial Paidos.

Winnicott, D. (1971) Clínica Psicoananlítica infantil. Buenos Aires. Editorial Hormé.

Winnicott, D. (1979) Realidad y Juego. Barcelona. Editorial Gedisa. 